Universidad de Lima

Facultad de Comunicación

Carrera de Comunicación

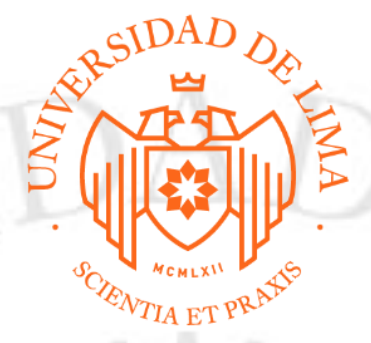

\title{
GESTIÓN DE CRISIS DESDE EL ÁMBITO COMUNICACIONAL EN EL CASO DEL
}

\section{ACCIDENTE DE "VIAJE LINDO AIRLINES"}

Trabajo de Suficiencia Profesional para optar el Título Profesional de Licenciado en Comunicación

Jose Luis Alejandro Iraha Flores

Código 20050594

$$
\text { Lima - Perú }
$$

17 de octubre de 2019 


\section{GESTIÓN DE CRISIS DESDE EL ÁMBITO COMUNICACIONAL EN EL CASO DEL ACCIDENTE DE "VIAJE LINDO AIRLINES"}




\section{INDICE ÍNDICE}

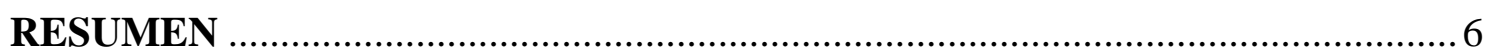

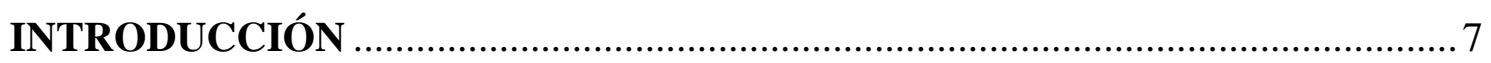

1. ANTECEDENTES DEL TRABAJO

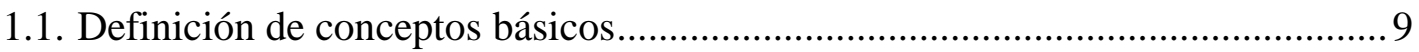

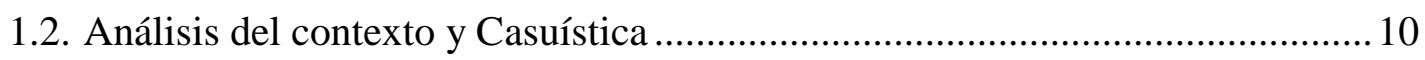

1.2.1. Análisis del caso................................................10

1.2.1.1. Eventos prometedores................................ 10

1.2.1.2. Crisis frente a fallos en la flota ...............................10

1.2.1.3. Errores de comunicación y trascendidos....................... 11

1.2.2. Casuística referencial ......................................... 12

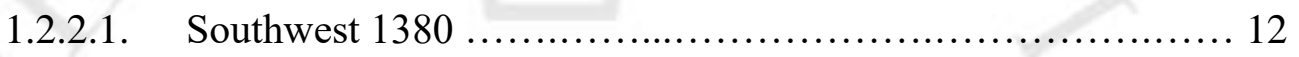

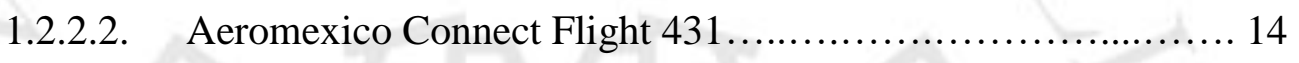

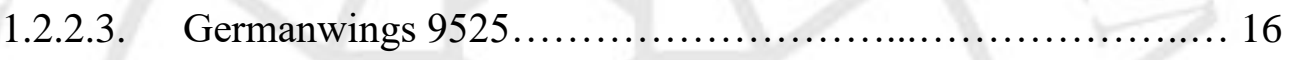

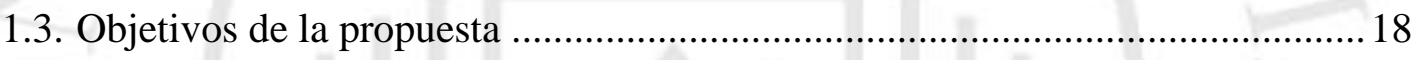

\section{PROPUESTA DE COMUNICACIÓN}

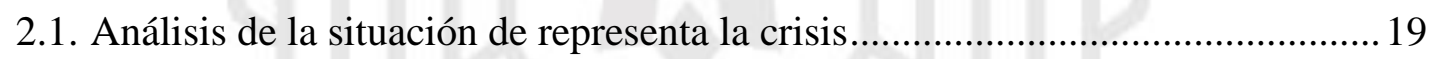

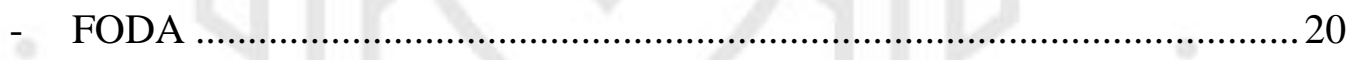

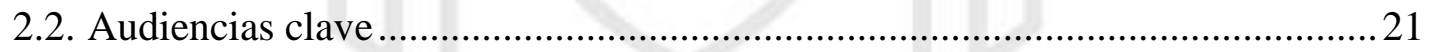

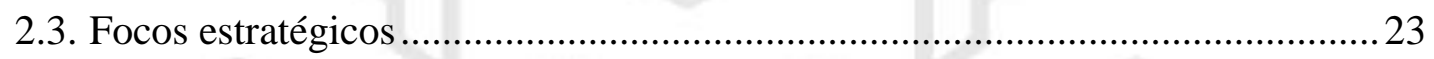

2.3.1. Abordaje del contexto y manejo de crisis .........................23

2.3.2. Capitalización y prevención de crisis ............................... 23

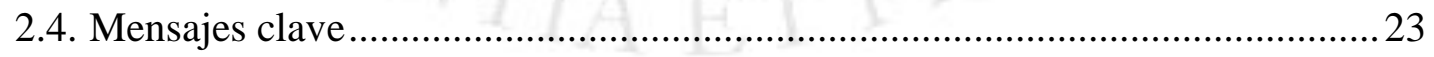

2.4.1. Transversales .................................................24

2.4.2. Específicos...................................................24

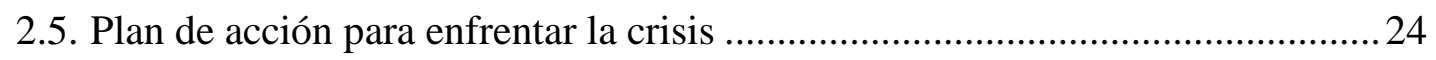

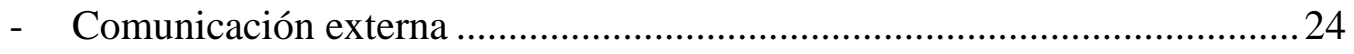

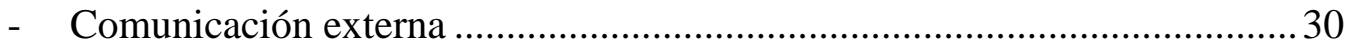

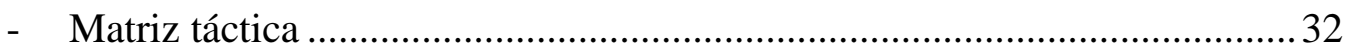

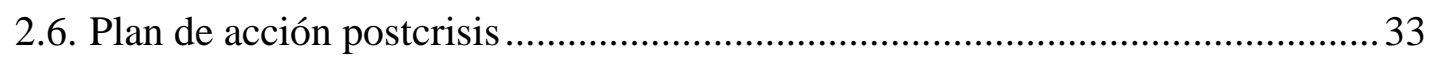


- Matriz táctica

.35

\section{Justificación}

3.1. Justificación del plan de acción frente a la crisis ............................................... 36

3.2. Justificación de estrategias para el control de daños y prevención de la crisis . 36

3.2.1. Justificación de estrategias para el control de daños

3.2.2. Justificación de estrategias para de prevención de la crisis 37

4. Recomendaciones 39

5. Referencias 41

6. Listado de Anexos 42 
Dirección web de las piezas y producciones de comunicación parte del trabajo

https://drive.google.com/open?id=1KEVSXJWI4bIzyhvZRVBMntxHO4YftUZ3 


\section{RESUMEN}

Los accidentes aéreos son una de las situaciones más graves que puede sufrir una aerolínea y sus clientes; en ese sentido, la empresa Viaje Lindo Airlines debe estar preparada para enfrentarlas en cualquier momento de su operación. El reto comunicacional resulta enorme cuando la crisis por accidente llega y no se cuentan con las estrategias establecidas para hacerle frente, por lo que se debe actuar sobre la marcha y prevenir futuros casos similares con un plan estructurado, basado en la mala experiencia vivida, con el fin de salvaguardar la reputación que se había obtenido.

Palabras clave: crisis, aerolínea, comunicación, corporativa, gestión, control, daños

Air accidents are one of the most serious situations that an airline and its customers can suffer; in that sense, the company Viaje Lindo Airlines must be prepared to face them at any time during its operation. The communication challenge is enormous when the accident crisis arrives and there are no established strategies for the control front, so the company must act when the circumstances are happening and prevent similar future cases with a structured plan, based on the bad experience lived, in order to safeguard the reputation that it had gained.

Keywords: crisis, airline, communication, corporate, management, control, damage 


\section{INTRODUCCIÓN}

El presente trabajo establece la gestión adecuada de la crisis suscitada en la aerolínea Viaje Lindo Airlines debido a un accidente aéreo de proporciones trágicas. Con el desarrollo de una estrategia comunicacional de alto impacto, la organización podrá garantizar, por una parte, la sostenibilidad del negocio y, por otra parte, recuperar la confianza de sus clientes y stakeholders. La comunicación se convierte en una herramienta fundamental para salvaguardar la reputación ganada a lo largo de sus años de operación en el mercado peruano.

Se han establecido acciones inmediatas para enfrentar la crisis, así como una matriz táctica, para el siguiente año, con la finalidad de controlar los daños directos e indirectos de la situación coyuntural y a la vez lograr la prevención de crisis probables o potenciales. Esta crisis marca un hito en la historia de Viaje Lindo Airlines, por lo que se hace vital capitalizar los aprendizajes, lo que llevará a un fortalecimiento corporativo. 


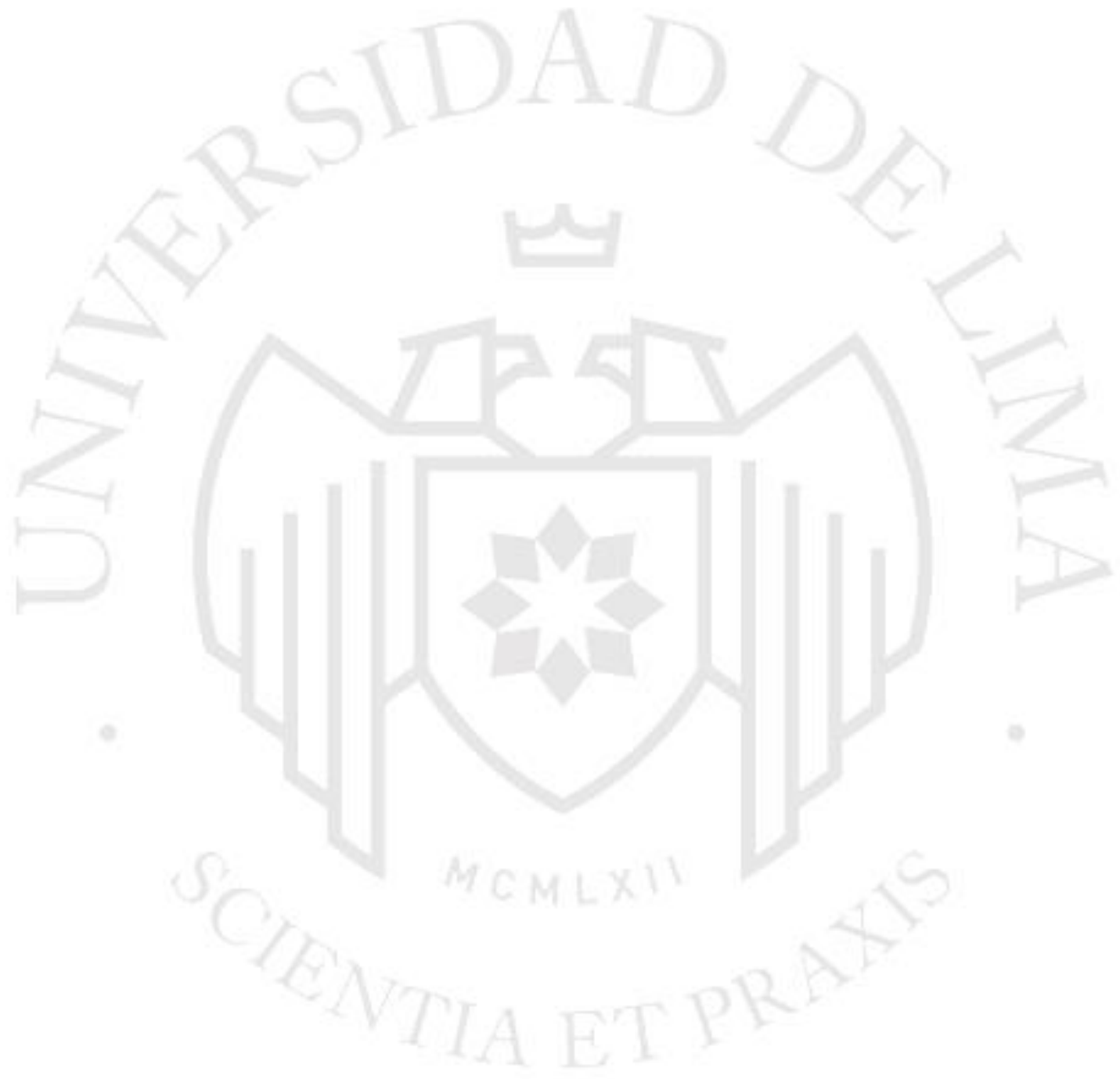




\section{ANTECEDENTES DEL TRABAJO}

\subsection{Definición de conceptos básicos}

Previo al análisis del caso que motiva a la realización del presente trabajo, es necesario introducir la terminología que se mencionará en el cuerpo del mismo, de manera recurrente.

Para entender lo que representa afrontar una crisis como la que se analizará, se requiere comprender este concepto, el cual es definido como la serie de acontecimientos anormales que tiene consecuencias sobre el funcionamiento de una organización y "se corresponden con una situación repentina de cambio", lo que pone en riesgo la estabilidad natural de la entidad y afecta a la totalidad de su estructura. Entre sus características principales, resaltan que sus fuentes de origen son diversas e imprevisibles y su tratamiento tiene carácter de urgencia, por lo que la toma de decisiones puede verse alterada de su orden natural (Calahorro, 2006).

Por otro lado, y de acuerdo a ICETEX (2010), estas pueden clasificarse de la siguiente manera:

- Crisis evitables: aquellas cuya ocurrencia puede prevenirse a través de una actuación eficaz en la víspera, y que se originan mayoritariamente por acciones de los seres humanos.

- Crisis no evitables: también referidas como accidentales, su origen se encuentra primordialmente en la naturaleza o fatalidad.

Asimismo, las crisis actuales se dan en un contexto mucho más exigente, en el que la sociedad está inmersa en una transformación digital, que conlleva nuevos mecanismos de interacción como las redes sociales, las que han permitido una mayor conectividad en las personas, pero también un uso desmedido de informaciones de todo tipo. La hiperconectividad es la constante y las organizaciones están en medio de ella, teniendo que ser actores sociales mucho más expuestos y dinámicos. De acuerdo con Castells (1997), la era actual es denominada la "Sociedad de la Información", dada la producción, desarrollo y 
transmisión de la información, las mismas que se han convertido en fuentes primordiales para la productividad y el poder.

Este marco exige dos nuevos imperativos comunicacionales para las organizaciones; por un lado, que ofrezcan a sus interlocutores diversos mecanismos de interacción ágiles, claros y oportunos, y, por otro lado, que gestionen su imagen corporativa, la que cada día está más expuesta y sensible a la opinión pública.

Las empresas están logrando, en la mayoría presionadas por las crisis, un mayor grado de conciencia acerca de la necesidad de contar con una estrategia vinculante entre la comunicación interna y la externa, lo cual es apoyado por Díaz Meco, citado por la Federación Asturiana de Empresarios.

"Se trata, sin duda, de dos caras de la misma moneda. Sin una apuesta decidida y sincera por la primera, es imposible proyectar a largo plazo una buena imagen externa y construir una sólida reputación corporativa" (Federación Asturiana de Empresarios, 2016).

\subsection{Análisis del contexto y casuística}

\subsubsection{Análisis del caso}

\subsubsection{Eventos prometedores}

Viaje Lindo Airlines (VLA), aerolínea tradicional que opera en el país desde 1995, ha sido una empresa de capitales peruanos con un crecimiento exponencial en operaciones aéreas, lo que se ha visto reflejado en el número de aeronaves y de destinos a lo largo y ancho del país.

Es bajo este fortalecimiento que, a inicios de 2019, la aerolínea solicitó se adquieran 15 aviones Boeing 737-300, adicionales a los 15 con los que ya se contaban de la serie 200 y a los 10 BAe 146-300. A partir de la entrega de esta nueva flota en la primera semana de junio del mencionado año, el futuro de la empresa era, a todas luces, prometedor: VLA podría convertirse en un gran competidor en el mercado. 


\subsubsection{Crisis frente a fallos en la flota}

Sin embargo, en junio del presente año, la empresa Boeing anunció la presencia de fallos en las alas en un reducido número de sus aviones 737 , lo que deviene en el funcionamiento de estas partes y la aerodinámica de la aeronave durante el despegue y aterrizaje. Habiendo estos fallos sido dados a conocer mediante un comunicado de Boeing Communications y a través de diversos medios de comunicación, la información no llegó inmediatamente a manos de las personas encargadas en las áreas respectivas de VLA.

La crisis estalló cuando, el domingo 9 de junio a las 7:35 a. m., un vuelo de Lima-Arequipa con 142 pasajeros a bordo, 6 tripulantes y 2 pilotos tuvieron que aterrizar de emergencia sobre la ciudad de Socosani, ante una pérdida de control de la aeronave reportada por el piloto. El hecho trajo el saldo de 67 pasajeros y 3 tripulantes de cabina fallecidos y múltiples heridos que fueron trasladados de emergencia a los hospitales cercanos.

\subsubsection{Errores en comunicación y trascendidos}

Frente a estos lamentables hechos, VLA cometió una serie de errores que lo pusieron en el ojo de la tormenta. La suma de las siguientes situaciones representa el reto comunicacional que la Gerencia de Comunicaciones enfrentará:

- Tardanza en la comunicación de la aerolínea frente a la opinión pública.

- Deslinde de responsabilidades pese a no haber existido un flujo continuo en la comunicación entre áreas.

- Gabinete de crisis inoperativo pese a la naturaleza de las operaciones de la empresa.

- Nota de prensa y rueda con periodistas improductivas e improvisadas.

- Vocero con bajas habilidades de comunicación.

Asimismo, se conocen otros datos que contribuyen al golpe de la imagen de VLA, tales como:

- Rumores a la prensa sobre malas condiciones laborales para con los trabajadores de VLA. 
- Amplia difusión de memes relacionados al accidente, que afectaron la reputación de la aerolínea.

- Posibles problemas legales contra las personas que sean encontradas como responsables dentro de la organización.

\subsubsection{Casuística referencial}

En las últimas dos décadas el mundo ha experimentado más de cuarenta accidentes aéreos afectando a más de treinta y cinco compañías del rubro, dejando un lamentable saldo de centenares de decesos de pasajeros.

Es evidente que la preocupación central ha de ser direccionada la valoración y el pesar que supone las pérdidas de vidas humanas. Sin embargo, dichas tragedias han permitido realizar casos de análisis desde en el ámbito comunicacional, convirtiéndose en experiencias que suponen la línea base para el accionar en la comunicación de crisis, evidenciando la preponderancia de la gestión de la reputación corporativa, evidenciando ejemplos de respuestas idóneas que permitieron mitigar los impactos comunicacionales de dichos sucesos, pero también otras que terminaron siendo en sí mismas también una catástrofe.

Para el presente caso de estudio, resulta pertinente ingresarnos en tres casos de gestión de crisis que resultan ilustrativos para un manejo idóneo de dichas situaciones.

\subsubsection{Southwest 1380}

El 17 de abril de 2018, el vuelo 1380 de Southwest Airlines, un Boeing 737-700, en ruta desde el aeropuerto La Guardia de Nueva York a Dallas Love Fiel, experimentó una falla incontenible del motor $\mathrm{N}^{\circ} 1$ (izquierda) a 20 minutos de vuelo. Los escombros dañaron el fuselaje y rompieron una ventana, causando una rápida despresurización de la cabina. Un pasajero sentado junto a la ventana fue parcialmente aspirado por la ventana y murió, mientras que otros ocho pasajeros sufrieron lesiones leves.

La tripulación inició un descenso de emergencia y se desvió al Aeropuerto Internacional de Filadelfia, donde el avión aterrizó sin problemas. Fue el 
primer accidente aéreo fatal para una aerolínea estadounidense desde el accidente del vuelo 3407 de Colgan Air en febrero de 2009, y el primer accidente que involucró a Southwest Airlines con la muerte de un pasajero.

También fue la primera vez que un pasajero a bordo de un vuelo transmitió imágenes de una crisis en desarrollo en "tiempo real", utilizando el servicio Wifi a bordo de la aerolínea. El pasajero Marty Martínez pagó el cargo de conexión de \$8 y se puso en marcha una transmisión en Facebook para despedirse de familiares y amigos, suponiendo que el avión se estrelle. El video fue ampliamente compartido en redes sociales y canales de noticias, junto con imágenes gráficas de la cabina de pasajeros y externas, siendo también publicado el daño por otros pasajeros después del aterrizaje.

El equipo de comunicaciones de Southwest, que ya había sido alertado por el centro de operaciones, comenzó a recibir llamadas de los medios a los pocos minutos de que Martínez apareciese en Facebook Live. Publicaron confirmación del incidente en los canales en línea de Southwest y continuó publicando declaraciones y videos actualizados a lo largo del día. Esto incluyó compartir contenido en canales de empleados que generaron más de 310,000 visitas a la página. Dos declaraciones en video del CEO Gary Kelly fueron el contenido más visto en la red interna de la aerolínea.

El interés posterior de los medios se centró en dos historias clave: la investigación del posible desgaste del metal en las aspas del ventilador del motor y el desempeño ejemplar de la tripulación, capitaneado por una piloto ex combatiente de la Marina de los EE. UU.

Southwest anunció su compromiso de revisar todas las aspas de los ventiladores dentro de 30 días y publicó un video en línea del proceso de mantenimiento. La aerolínea también emitió un comunicado de ambos pilotos, quienes ya habían sido identificados en la cobertura de noticias. 
La compañía cambió su marca digital a azul claro con un logotipo monócromo durante los primeros tres días y gradualmente hizo la transición a su personalidad normal después de 10 días. La publicidad y otras actividades promocionales fueron canceladas y 500,000 copias de la próxima revista en vuelo fueron desechadas para que la columna del CEO pudiera ser reescrita. El equipo de comunicaciones también "limpió" todas las fotos, material de archivo y otros activos para cualquier cosa que podría parecer inapropiado en las circunstancias.

En general, el accidente generó más de 45,000 "hits" en los medios y 260,000 menciones en las redes sociales. La cobertura de noticias fue principalmente $(56 \%)$ negativa, pero las conversaciones en las redes sociales fueron más equilibradas, con un $46 \%$ negativo, $32 \%$ neutral y $22 \%$ positivo.

En particular, la respuesta de comunicaciones de la aerolínea fue ampliamente elogiada por ser oportuna, empática y transparente.

\subsubsection{Aeromexico Connect Flight 2431}

Un Aeromexico Embraer ERJ190 operando un vuelo doméstico de Durango a Ciudad de México bajo la marca Aeromexico Connect se estrelló en el despegue, el 31 de julio de 2018, después de aparentemente encontrar cizalladura del viento del "microburst" sobre el aeródromo. El ERJ190 acababa de despegar cuando perdió altitud y se estrelló al final de la pista. Los 103 pasajeros y la tripulación a bordo sobrevivieron, aunque el avión fue destruido por el fuego.

Algunos pasajeros sufrieron heridas graves, pero la mayoría escapó relativamente ilesa. Múltiples sobrevivientes comenzaron a publicar fotos en las redes sociales inmediatamente después de escapar de los restos, mientras que otros transmitieron imágenes de ellos mismos en la escena del accidente en Facebook Live, incluso cuando el fuego se apoderó. Un pasajero filmó toda la secuencia de accidentes y evacuación desde el interior de la cabina, siendo el video publicado en línea y reproducido por 
canales de noticias principales. Los equipos de televisión también llegaron rápidamente a la escena y comenzaron a entrevistar a los sobrevivientes sobre su experiencia "cercana a la muerte".

El accidente ilustró el desafío al que se enfrentan las aerolíneas al intentar influir en la cobertura que se desarrolla de un accidente o incidente mayor en la era digital. El equipo de comunicación de Aeroméxico en la oficina central recibió su primera alerta 34 minutos después del accidente, momento en el que las fotos y el video del accidente y las secuelas ya eran visibles para una audiencia global y los sobrevivientes fueron entrevistados en los principales canales de noticias. La primera confirmación "oficial" llegó en un tweet del Gobernador del Estado de Durango, quien posteriormente se convirtió en una de las principales fuentes de información para los medios. Un minuto después, la aerolínea emitió su primera declaración en Twitter y otros canales.

La cobertura mediática temprana fue crítica con Aeroméxico, destacando las quejas sobre la falta inicial de información. Sin embargo, el tono de los informes cambió una vez que Aeroméxico centró la comunicación en el hecho de que todos los que estaban a bordo del ERJ190 sobrevivieron y sus esfuerzos para ayudar a los afectados, incluidos los miembros de la tripulación.

Aeroméxico también decidió trabajar en colaboración con el gobernador del estado y otras entidades locales y les facilitó ayuda para confirmar información como el estado de las personas lesionadas y cuándo fueron dados de alta del hospital.

El CEO de Aeroméxico realizó una conferencia de prensa a las 9:00 pm del mismo día del accidente. Entonces se encontró con el gobernador en Durango la mañana siguiente y celebró una conferencia de prensa conjunta. En sus declaraciones públicas, la aerolínea también reconoció el apoyo de las autoridades locales para responder al accidente. 
Más de 4.000 noticias aparecieron, la mayoría de las cuales incluían fotos y videos tomados por pasajeros. Pero sólo el $8 \%$ de la cobertura mediática fue negativo, con el enfoque principal en la evacuación exitosa y el apoyo de la aerolínea a los sobrevivientes.

El impacto en la reputación de Aeroméxico fue mínimo, como lo demuestra el aumento de $1.8 \%$ en el precio de las acciones de la aerolínea tres días después del accidente.

\subsubsection{Germanwings 9525}

La respuesta continua del Grupo Lufthansa al colapso de Germanwings en 2015 es un recordatorio valioso de la necesidad de las aerolíneas deben pensar detenidamente sobre cómo manejarían el impacto a largo plazo de una pérdida importante y la continuidad de su compromiso con las personas y comunidades que se vieron directamente afectadas.

En la mañana del 24 de marzo de 2015, el vuelo 4U9525 de Germanwings, un Airbus A320-200, despegó del Aeropuerto El Prat de Barcelona con 144 pasajeros y seis tripulantes a bordo. El A320 se dirigía a Dusseldorf pero inesperadamente comenzó un descenso controlado, chocando contra una montaña en los Alpes franceses a $100 \mathrm{~km}$ al noroeste de Niza.

Pronto se supo que se trataba de un acto deliberado del copiloto Andreas Lubitz, que había bloqueado al capitán de la cabina del piloto. Desconocido para la aerolínea, Lubitz había estado recibiendo tratamiento psiquiátrico y había sido declarado no apto para volar por su médico.

Germanwings (desde entonces absorbida por la compañía hermana Eurowings) fue la subsidiaria de bajo costo de corto alcance del Grupo Lufthansa. Sus procedimientos de gestión de crisis exigen que el Operador "tome la iniciativa" en la respuesta después de un accidente, incluida la comunicación. Bajo las circunstancias, la política fue reemplazada por la necesidad de que Lufthansa Group tome el control. 
El presidente y CEO de Lufthansa Group, Carsten Spohr, un ex piloto del A320 que aún posee la licencia de capitán y graduado del mismo centro de entrenamiento de vuelo de Lufthansa en Bremen como Lubitz, se convirtió en la "cara y voz" de la respuesta. Su desempeño como portavoz principal de Lufthansa y su evidente sorpresa de que un compañero piloto había causado la tragedia, fue ampliamente visto como un factor clave para contener cualquier daño reputacional al Grupo.

Pero después de que el impacto inicial se desvaneció, Lufthansa aún enfrentó el desafío de demostrar su compromiso duradero con las familias de los pasajeros y la tripulación. Se estableció una organización postemergencia, con 15 diferentes flujos de trabajo para gestionar todas las cuestiones relacionadas con el vuelo 9525, incluida la comunicación familiar, la devolución de pertenencias, memoriales y apoyo financiero. Se creó un Fondo de ayuda de 15 millones de euros tres meses después del accidente, con un Consejo de administración independiente que incluía representantes de la familia. El objetivo era apoyar la educación de niños que perdieron a sus padres a bordo, pero también proporciona fondos adicionales para familias en dificultades y proyectos vinculado con la memoria de las víctimas individuales.

Un enfoque importante fue involucrar a las familias en la creación de ceremonias y símbolos conmemorativos apropiados en las múltiples ubicaciones conectadas con el vuelo 9525. Esto incluyó el lanzamiento de una competencia de diseño para solicitar un memorial permanente en la escena del accidente, que es inaccesible y solo se puede ver desde la distancia. El "Orbe Solar" de cinco metros lleno de recuerdos personales de las víctimas fue presentado en el segundo aniversario de la tragedia en una ceremonia a la que asistieron familias, uno de los cuatro sitios conmemorativos en el área. Otros memoriales permanentes fueron creados en Alemania y España.

Los principios centrales de Lufthansa durante la fase posterior a la emergencia han sido actuar con "transparencia, honestidad y humanidad". También se ha comunicado regularmente con las familias en sus propios 
idiomas, a través de múltiples canales incluyendo un sitio web familiar seguro. La aerolínea también se ha comprometido a respetar las opiniones de las familias sobre todas las claves decisiones, y para mantener relaciones cercanas con las autoridades en cada ubicación, particularmente cerca del sitio del choque.

Como se observa, complejidad de la comunicación en escenarios de crisis se torna inmensa, dado que tiende a desatar posturas negativas de parte de distintas audiencias y pone a prueba la capacidad de reacción de las empresas y las convierte en factor determinante. Es evidente que esta se intensifica en el caso de la industria aérea la cual en sí misma se muestra bastante vulnerable por estar expuestos a tragedias de enormes dimensiones. En ese contexto, la Asociación Internacional de Transporte Aéreo ha diseñado un manual que ha socializado con las líneas aéreas afiliadas que sirva como línea base para la ejecución de acciones de prevención, mitigación y respuesta ante sucesos que puedan derivar en crisis reputacionales potenciales.

Es preciso contemplar también el hecho de que, a diferencia de décadas pasadas, los flujos de información que recorren en tiempo real a través de la internet hacen que las redes sociales desempeñen un papel central y supongan un escenario de agravamiento de las crisis. En tal sentido, la gestión de estas plataformas como frente de combate resulta importantísimo.

\subsection{Objetivos de la propuesta}

El objetivo principal del presente trabajo es diseñar y desarrollar una estrategia comunicacional durante y después de la crisis de Viaje Lindo Airlines para, de esta manera, salvaguardar su reputación y mantener el posicionamiento de la compañía, frente al contexto difícil surgido a partir del trágico accidente aéreo.

El cumplimiento de este objetivo está a cargo de la Gerencia de Comunicaciones de VLA, con el respaldo de la alta dirección. 
En ese sentido, se analizarán todos los detalles del caso a partir de la información brindada, con el fin de ejecutar las estrategias adecuadas a nivel interno y externo, y de cara a los stakeholders de la organización.

\section{PROPUESTA DE COMUNICACIÓN}

\subsection{Análisis de la situación que representa la crisis}

Frente a la falta de precisión y certeza en la gestión comunicacional en las primeras horas de explotada su crisis organizacional, Viaje Lindo Airlines tiene en contra a la opinión pública, que plasma su descontento en redes sociales, principalmente, a través de los ampliamente utilizados memes, que afectan gravemente la imagen y reputación de la empresa.

Asimismo, es un gran error lanzar productos comunicacionales con retraso y a través de un discurso inconsistente, en el que la responsabilidad por el accidente aéreo no es asumida. Esta situación debió ser evaluada de una manera más estratégica por la alta dirección de la empresa antes de autorizar la difusión de la nota de prensa para los medios de comunicación, pues la imagen reflejada será de "lavado de manos", lo que provoca una mayor resistencia entre la población hacia Viaje Lindo Airlines.

Por otro lado, resulta gravísimo que, frente a la naturaleza de las funciones de la empresa, el gabinete de crisis se encuentre inoperante, y que el plan de crisis no haya sido actualizado ni socializado transversalmente en la organización.

Las conferencias de prensa, si bien son una herramienta de contacto directo con la prensa y que demuestran cercanía con los medios de comunicación y sus respectivas audiencias, también son una fuente de exposición en caso de que los voceros no se encuentren lo suficientemente preparados a nivel informativo y de habilidades comunicacionales. Esto último ocurrió con VLA, lo que resultó contraproducente, y agudiza una imagen de inseguridad e improvisación de la aerolínea, de cara a la población. 
La importancia de realizar las encuestas de clima laboral y ejecutar mejoras en las condiciones de los colaboradores a partir de las mismas, tiene efectos que pueden hacerse más evidentes en etapas de crisis. En una situación como esta, en la que la vulnerabilidad de la entidad creció exponencialmente, aquellos trabajadores que no están comprometidos ni identificados con VLA aprovecharon para filtrar los principales descontentos internos y sumarse a la ola de situaciones cuestionables contra la empresa, agravando, así, la crisis institucional.

\begin{tabular}{|c|c|c|c|}
\hline & FORTALEZAS & & DEBILIDADES \\
\hline F1 & $\begin{array}{l}\text { Tiene como valor diferencial la } \\
\text { seguridad en sus viajes }\end{array}$ & D1 & $\begin{array}{l}\text { Fragilidad del área de comunicaciones } \\
\text { y su planificación }\end{array}$ \\
\hline $\mathbf{F} 2$ & $\begin{array}{l}\text { La puntualidad es otro pilar } \\
\text { diferenciador ante su competencia }\end{array}$ & D2 & Inoperatividad del gabinete de crisis \\
\hline F3 & $\begin{array}{l}\text { Buen posicionamiento frente al } \\
\text { público }\end{array}$ & D3 & $\begin{array}{l}\text { Tenencia de un manual de crisis } \\
\text { desactualizado y desconocimiento de } \\
\text { este }\end{array}$ \\
\hline F4 & $\begin{array}{l}\text { Tenencia de redes sociales y página } \\
\text { web activas }\end{array}$ & D4 & $\begin{array}{l}\text { Personal descontento con las } \\
\text { condiciones laborales }\end{array}$ \\
\hline F5 & App con buena acogida & D5 & $\begin{array}{l}\text { Poca inversión publicitaria que no } \\
\text { contribuye a fortalecer } \\
\text { posicionamiento de la empresa }\end{array}$ \\
\hline F6 & $\begin{array}{l}\text { Reportes GRI positivos en los } \\
\text { últimos años }\end{array}$ & D6 & Baja cantidad de rutas nacionales \\
\hline \multicolumn{2}{|r|}{ OPORTUNIDADES } & \multicolumn{2}{|r|}{ AMENAZAS } \\
\hline 01 & $\begin{array}{l}\text { Reconocimientos y premios por su } \\
\text { sensibilidad ambiental }\end{array}$ & A1 & $\begin{array}{l}\text { Percepción negativa de las audiencias } \\
\text { luego de la primera intervención GG }\end{array}$ \\
\hline $\mathbf{O 2}$ & $\begin{array}{l}\text { Fortalecimiento de la flota por nueva } \\
\text { adquisición de aeronaves }\end{array}$ & A2 & $\begin{array}{l}\text { Masificación de comentarios negativos } \\
\text { en redes sociales }\end{array}$ \\
\hline
\end{tabular}




\begin{tabular}{|c|l|l|l|}
\hline O3 & $\begin{array}{l}\text { Posibilidad de operación de nuevas } \\
\text { rutas nacionales ante aumento de } \\
\text { flota }\end{array}$ & A3 & $\begin{array}{l}\text { Ingreso de aerolíneas low-cost al } \\
\text { mercado peruano }\end{array}$ \\
\hline
\end{tabular}

\subsection{Audiencias Clave}

\begin{tabular}{|c|c|c|}
\hline UBICACIÓN & GRUPO & EXPECTATIVAS Y NECESIDADES \\
\hline \multirow{3}{*}{ INTERNAS } & $\begin{array}{l} \\
\text { Personal } \\
\text { Administrativo }\end{array}$ & $\begin{array}{l}\text { Suponen el eje fundamental para la empresa. No sólo porque son la fuerza } \\
\text { operativa de las acciones organizacionales, sino principalmente porque de la } \\
\text { consolidación de una cultura sólida dependen los cimientos de la identidad } \\
\text { corporativa que se pretende instaurar para el logro de una imagen corporativa } \\
\text { potente. } \\
\text { Resulta imperante la mitigación de su incertidumbre, de cara a la ejecución } \\
\text { de los planes futuros. }\end{array}$ \\
\hline & $\begin{array}{l}\text { Tripulantes } \\
\text { Pilotos }\end{array}$ & $\begin{array}{l}\text { Constituyen la principal cara visible de la organización. De sus certezas, } \\
\text { equilibrio y alineamiento con los objetivos depende la consolidación de la } \\
\text { imagen corporativa. Son el ineludible nexo directo con los clientes, quienes } \\
\text { llevan consigo la principal búsqueda de confianza, a partir de las dudas y } \\
\text { miedos que se han instalado en sus racionales colectivos, por lo que su } \\
\text { convencimiento es fundamental para la hacer extensivo y persuadir a los } \\
\text { usuarios de los esfuerzos y compromisos asumidos por la organización. } \\
\text { Llevan a cuesta la principal incertidumbre de lo venidero, toda vez que son } \\
\text { ellos quienes van al frente y asumen las responsabilidades de las promesas } \\
\text { que la compañía profesa. } \\
\text { han sufrido la debilitación de su equipo y es inevitable que sus mentes } \\
\text { alberguen la idea de "pudieron haber sido ellos". }\end{array}$ \\
\hline & Alta Dirección & $\begin{array}{l}\text { Son los encargados de la dirección de la empresa y de su alineamiento con la } \\
\text { identidad y los objetivos organizacionales depende el afianzamiento y } \\
\text { fortalecimiento de la empresa. } \\
\text { Frente al contexto, suponen la piedra angular del direccionamiento } \\
\text { estratégico futuro y son los llamados a sostener la reputación empresa por } \\
\text { depender de ellos la toma de decisiones, pero sobre todo porque en muchos } \\
\text { casos sobre ellos recaerá la ofensiva de los stakeholders. }\end{array}$ \\
\hline \multirow[b]{2}{*}{ INTERMEDIAS } & Víctimas & \multirow{2}{*}{$\begin{array}{l}\text { Constituyen el grupo más afectado con los hechos suscitados. Son quienes } \\
\text { guardan el principal sentimiento de decepción de las promesas de la empresa. } \\
\text { Suponen la audiencia a la cual deben estar orientados los principales } \\
\text { esfuerzos de atención de necesidades por parte de la compañía y el grupo más } \\
\text { difícil de recuperar. } \\
\text { Sus percepciones y mensajes son las que generarán el mayor impacto en la } \\
\text { imagen y reputación de la marca. }\end{array}$} \\
\hline & $\begin{array}{l}\text { Familiares de } \\
\text { las víctimas }\end{array}$ & \\
\hline
\end{tabular}




\begin{tabular}{|c|c|c|}
\hline & $\begin{array}{l}\text { Entes } \\
\text { reguladores del } \\
\text { sector }\end{array}$ & $\begin{array}{l}\text { Son los entes encargados de la regulación de las políticas relacionadas al } \\
\text { sector. El correcto relacionamiento con estos permitira no sólo una gestión } \\
\text { eficiente y efectiva a la empresa, sino que también permitirá generar sinergias } \\
\text { en pos de la mejora del sector. } \\
\text { Frente al contexto, son quienes más demandarán, exigirán y cuestionarán los } \\
\text { sucesos, pero sobre todo la continuidad de las operaciones. Resulta imperante } \\
\text { una interacción transparente y colaborativa durante la crisis y el redoble de } \\
\text { esfuerzo en la recuperación y/o entablamiento de relaciones de confianza con } \\
\text { estos. } \\
\text { - Ministerio de Transportes y Comunicaciones (Dirección General de } \\
\text { Aviación Civil - DGAC / Comisión de Investigación de Accidentes } \\
\text { de Aviación / CIAA), Ministerio de Ambiente, Poder Judicial, } \\
\text { IATA, SERPAR, entre otros }\end{array}$ \\
\hline & Proveedores & $\begin{array}{l}\text { Son los facilitadores del equipamientos y servicios necesarios para la } \\
\text { prestación del servicio. Del trabajo con ellos depende principalmente el } \\
\text { cambio en los procesos y el cumplimiento de las promesas que la compañía } \\
\text { asume con los usuarios. Es urgente el cambio del mindset de los que } \\
\text { actualmente trabajan con nosotros, toda vez que el accidente ha ocurrido por } \\
\text { un error netamente de la compañía que ha puesto en el ojo de la tormenta a } \\
\text { uno de ellos (Boeing), lo cual podría generar incertidumbre y desconfianza } \\
\text { en ellos. } \\
\text { Resulta pertinente el repaso de los compromisos interdependientes y el } \\
\text { alineamiento de prácticas y procesos ejecutados de forma conjunta para el } \\
\text { afianzamiento de las relaciones y en pos de una gestión coherente con } \\
\text { nuestras promesas organizacionales. }\end{array}$ \\
\hline \multirow{3}{*}{ EXTERNAS } & $\begin{array}{l}\text { Clientes } \\
\text { Usuarios }\end{array}$ & $\begin{array}{l}\text { Son el principal flanco de cuestionamiento de los servicios, las promesas y } \\
\text { accionar de la empresa, en tanto sus expectativas se han visto desencantadas } \\
\text { a partir de los sucesos. } \\
\text { Si bien la fidelización de de estos en un sector como el que se desempeña } \\
\text { VLA resulta complicado, los sucesos ocurridos no hacen sino impactar } \\
\text { negativamente sus percepciones, haciendo que predominen las dudas } \\
\text { respecto de los procesos y servicios, además de acrecentar la asociación de la } \\
\text { marca con la inseguridad, por lo que son una audiencia de quien costará } \\
\text { mucho reestablecer los lazos de confianza pero hacia quienes deben } \\
\text { orientarse fuertemente los esfuerzo de persuasión y moldeamiento de la } \\
\text { imagen y reputación. }\end{array}$ \\
\hline & Competencia & $\begin{array}{l}\text { Suponen siempre el marco de referencia para la medición de las acciones de } \\
\text { la empresa. A su vez son un motor de impulso para la mejora continua en la } \\
\text { gestión de la empresa a partir de la competencia. } \\
\text { Ante la situación, a pesar de ser un hecho que enluta al sector, es inevitable } \\
\text { que estas pretendan capitalizar el contexto para ganar cuota de mercado, } \\
\text { convirtiéndose un flanco de ataque potente que comprometería la reputación } \\
\text { de la empresa a partir del aprovechamiento a través de la comparación de } \\
\text { servicios y cumplimiento de promesas. }\end{array}$ \\
\hline & $\begin{array}{l}\text { Medios de } \\
\text { comunicación }\end{array}$ & $\begin{array}{l}\text { Son unos de los grupos, sino el que más, con mayor poder frente a la sociedad. } \\
\text { Su alcance puede permitirnos llegar a un público amplio y logra el } \\
\text { acercamiento que se desea, pero también es plausible el riesgo que su } \\
\text { comunicación en situaciones de crisis masifique los impactos negativos. }\end{array}$ \\
\hline
\end{tabular}




\subsection{Focos Estratégicos}

\subsubsection{Abordaje del contexto y manejo de crisis}

\section{Objetivos}

- Atender las demandas de información de los stakeholders

- Responder y solucionar las necesidades inmediatas de las audiencias clave.

- Mitigar los impactos negativos derivados de la crisis

- Desarrollar respuestas comunicacionales a todos los flancos $\quad$ de riesgo potenciales

2.3.2. Capitalización y prevención de crisis

\section{Objetivos}

\section{- Salvaguardar la reputación de la compañía}

- Reducir la incertidumbre de los usuarios relacionada al servicio.

- Deslindar la asociación de la marca con inseguridad

- Lograr un relacionamiento eficiente y eficaz con los distintos grupos de interés.

\section{- Consolidación de la personalidad corporativa}

Consolidar una cultura y estilo organizacional de la empresa.

Fortalecer la identidad institucional y sentido de pertenencia.

- Fortalecer el posicionamiento de la marca / compañía

- Posicionar la empresa como referente de la seguridad y consciente del impacto socioambiental de sus acciones.

- Generar notoriedad y visibilidad de la marca

\subsection{Mensajes Clave}

Los mensajes clave a ser utilizados en el acompañamiento de las acciones a proponerse estarán alineados las prioridades comunicacionales que se sustentan en las siguientes ideas fuerza:

- Tenemos la seguridad como el pilar organizacional fundamental.

- Somos conscientes del impacto socioambiental de nuestras acciones y nos conducimos comprometidos con el bienestar de las personas y el medio ambiente. 


\subsubsection{Transversales}

- "La seguridad de los usuarios es nuestra prioridad."

- "Hacemos lo correcto, conscientes siempre del impacto social de nuestras acciones."

\subsubsection{Específicos}

- "Seguridad = Compromiso"

- "Sólo piensa en tu destino. El trayecto SEGURO que será bueno."

- "Con seguridad, cada día estarán en nuestras memorias."

- "Eres nuestro radar más importante"

- "SEGURO que podemos"

- "Ganas y buen viento"

- "Preparando el despegue"

- "Amor por el aire." / "Vivimos del aire"

- "Vuela ligero"

- "Es tiempo de desconectar"

\subsection{Plan de acción para enfrentar la crisis}

Para afrontar esta crisis, que no fue prevenida dados los efectos que Viaje Lindo Airlines ha enfrentado desde que se desarrolló este acontecimiento, es necesario contar con un plan de acciones a desarrollarse en los 15 días siguientes, a fin de mitigar los riesgos de cara a los grupos de interés y en pro de la propia aerolínea.

De esta manera, en el futuro cercano, deben ejecutarse los frentes de acción: comunicación externa y comunicación interna.

\section{- Comunicación externa}

Las consecuencias a nivel externo han sido las más evidenciadas, dado a que están frente a los ojos de la opinión pública.

Para ello, se proponen los siguientes contenidos de comunicación externa, a fin de brindar una respuesta posterior al primer día infructuoso en cuanto a la gestión de crisis: 


\section{Pronunciamiento breve y conciso a través de redes sociales}

Las plataformas a explotar por su inmediatez son, en definitiva, las redes sociales. A través de ellas, se informará sobre cualquier nuevo dato que se tenga con respecto al accidente, en vista a que ya ha transcurrido un día infructuoso comunicacionalmente hablando, y que ha dejado más dudas que certezas.

Dado esto, el pronunciamiento después del accidente (ver anexo 1) debe darse a conocer a primera hora del lunes 10 de junio, a través de Facebook y Twitter, en el que se plasmarán los siguientes elementos:

Lamento por lo ocurrido y el pésame hacia los deudos.

- Asunción de la responsabilidad de los hecho y compromiso con la investigación

- Promesa de continuar comunicando paulatinamente las posteriores medidas que tomará la empresa hacia los familiares de las víctimas (entendiéndose como la indemnización por las pérdidas humanas y gastos en general, así como mayores datos sobre el accidente).

Esta táctica está dirigida a clientes, entidades gubernamentales y medios de comunicación, que estarán muy atentos a estas fuentes de información dada la coyuntura desatada frente al accidente.

\section{Ayuda memoria de la información necesaria y Q\&A's}

Estos productos comunicacionales son necesarios y relacionados a una explicación detallada del hecho.

En el caso del documento de ayuda memoria, se plasmarán mensajes clave que se alinearán a todas las tácticas de comunicación externas, relacionados a aceptación de las responsabilidades frente al accidente aéreo y a la colaboración por parte de VLA para con las investigaciones y deudos de los fallecidos y heridos, compromisos a asumir a partir de este accidente, entre otros datos de relevancia (ver anexo 2). 
Asimismo, la Gerencia de Comunicaciones elaborará un documento de preguntas y respuestas (Q\&A) con las principales preguntas que podrían hacer los medios de comunicación, a fin de que la respuesta esté alineada a lo que VLA desea comunicar (ver anexo 3).

Esta táctica está dirigida a clientes, entidades gubernamentales y medios de comunicación, que estarán muy atentos a estas fuentes de información dada la coyuntura desatada frente al accidente.

\section{Comunicado de prensa:}

Al ya haber una primera nota de prensa mal redactada y con la opinión pública en contra, este segundo recurso comunicacional debe contar con las siguientes características para un mejor efecto (ver anexo 4):

- La información necesaria debe brindarse de la manera más empática posible.

- Como se mencionó anteriormente, y alineados a los mensajes claves establecidos de acuerdo con la coyuntura, Viaje Lindo Airlines asumirá responsabilidad frente a lo ocurrido, con el firme compromiso de apoyar en todo lo que esté al alcance de la organización para con autoridades y los afectados.

- El mensaje a reforzar es que la aerolínea redoblará esfuerzos, políticas y estrategias para recuperar lo que siempre fue su valor diferencial: la seguridad.

- Se informará que se retirarán la flota de aviones Boeing 737 Max y, por ende, se modificarán las condiciones de las operaciones aéreas que estaban programadas mediante este modelo de transporte.

- Se difundirá una línea de contacto exclusiva para familiares de las víctimas y para medios de comunicación.

- Se brindará información sobre cambio de destinos y el reembolso para los pasajeros que deseen cancelar sus billetes tras el siniestro. 
Además del clásico envío de este material a los medios de comunicación, se utilizará Facebook y LinkedIn para su difusión. Esta táctica estará dirigida a clientes externos, organismos gubernamentales y medios de comunicación.

\section{Video de vocero a difundir en redes sociales}

Dada la coyuntura en la que los medios de comunicación pueden continuar preguntando sobre temas de diversa índole que pongan en jaque al dueño y gerente general de la empresa, la Gerencia de Comunicaciones elaborará una discurso claro, conciso, empático e informativo (ver anexo 5) que se socializará a través de un vídeo a difundirse mediante las redes sociales de la empresa y a los medios de comunicación. Este será brindado por el gerente.

Previo al video, se preparará una media training rápido. En tanto, el discurso se hará con base en la ayuda memoria previamente citada. Esta táctica tendrá implicancia hacia los clientes externos y medios de comunicación.

\section{Utilización de los logos en blanco y negro}

Los logos de la entidad deben ser utilizados en blanco y negro en las diversas redes sociales de la empresa (Facebook, Twitter, Instagram y LinkedIn), acompañados de un mensaje de pésame hacia los familiares (ver anexo 6).

Esto se dará con el objetivo de promover un ambiente de empatía, de asunción de errores y de compromiso de cara a los afectados. Esta táctica se encuentra dirigida a clientes externos.

\section{Conector VLA", el enlace directo con deudos}

Viaje Lindo Airlines designará un responsable de cara a los deudos, que estará encargado de mantener una comunicación directa con las víctimas del accidente aéreo, sus familiares y entorno íntimo. 
Esta información será obtenida de constantes reuniones con el gerente general de la empresa y cualquier área que esté relacionada directa o indirectamente con los hechos, siempre con presencia de la Gerencia de Comunicaciones. Tras ello, se definirán cuáles son las situaciones a informar a los deudos y de qué manera hacerlo. La idea es ofrecer una actitud empática y de real preocupación hacia ellos.

\section{Incluir una línea gratuita de $\mathbf{2 4}$ horas para comunicación externa:}

Dada la incertidumbre generada por la fluctuación de información a partir de los diversos canales de comunicación a los que la población tiene acceso hoy en día, es necesario generar un espacio de datos oficiales provenientes por Viaje Lindo Airlines.

La persona designada deberá ser bilingüe para atender posibles llamadas en inglés. Asimismo, también debe estar alineada con lo que se debe comunicar, por lo que se le alcanzará también el documento de preguntas y respuestas previamente citado.

\section{Implementación de dark-site}

Con el apoyo del área de TI, la web de Viaje Lindo Airlines mostrará, en su inicio, un pop-up (también llamado ventana emergente) con un mensaje de luto, que será el mismo que se colocó en redes sociales.

Este anuncio contará con un botón de "mayor información", el mismo que derivará al "dark site" (ver anexo 7). Esta página estará dedicada a la catástrofe acaecida, e incluirá datos como:

- Listado de difuntos y heridos.

○ Video del gerente general.

- Plug-ins que incluyan las redes sociales de la empresa, las cuales brindarán datos de interés de manera constante.

- Teléfono de contacto de 24 horas. 
○ Información sobre el "Conector VLA".

\section{Gira de entrevistas del vocero en los principales medios de comunicación}

Las comunicaciones de cara a la crisis, de manera posterior a la primera táctica de esta naturaleza, se desarrollarán a través de una gira de entrevistas a los principales medios de comunicación de radio, prensa y televisión nacional. El discurso y la actitud frente a esta acción será fortalecida con una sesión de media training y con la información base planteada en los documentos de ayuda memoria y el Q\&A.

La idea de estas entrevistas es informar las siguientes medidas:

- Reiteración de que la flota defectuosa de aviones ha sido suspendida hasta nuevo aviso.

- Garantizar el cumplimiento de la cobertura de las necesidades de las familias de los deudos y heridos.

- Mencionar qué estrategias internas se trabajarán para garantizar la seguridad de clientes internos y externos.

Informar sobre los lugares donde se puede encontrar mayor información, así como la creación del rol "Conector VLA", quien es el responsable de brindar asistencia e información a los deudos.

- Otros datos de relevancia y de acuerdo a la coyuntura.

\section{Información en aplicativo móvil}

El aplicativo móvil, al haber tenido tanta aceptación previa al accidente, comunicará todas las facilidades para modificar vuelos o solicitar reembolsos por parte de los usuarios que tengan viajes pendientes con VLA.

Es importante que, también, se aproveche esta plataforma para conectar de manera directa con el teléfono de emergencias para el entorno de las víctimas.

Fortalecimiento del servicio de monitoreo de noticias 
Es de vital importancia que la Gerencia de Comunicaciones potencie el seguimiento de las menciones directas e indirectas que se realicen sobre Viaje Lindo Aírlines. Esto implica un dedicado seguimiento en los medios tradicionales y virtuales, a fin de actuar ante cualquier posible rumor con nuevas comunicaciones de acuerdo a la naturaleza del intento de desinformación.

\section{- Comunicación interna}

Como se sabe, toda situación de crisis genera estragos en varias líneas, incluyendo la interna: los colaboradores de la organización. De acuerdo a como indican los antecedentes, existe un descontento entre los trabajadores de Viaje Lindo Airlines, lo cual debe ser atendido por la empresa.

En ese sentido, es importante que se implementen tácticas para aminorar el impacto negativo en la mayor medida posible. Por ello, se proponen las siguientes acciones:

\section{Comunicados internos}

A fin de regular el tránsito de rumores y comentarios desinformativos, elaborar un comunicado interno, informando y motivando a los colaboradores a mantener un ambiente de unidad y fortaleza frente a esta crisis.

\section{Rondas informativas a las áreas con apoyo de vocero interno}

Se designará al gerente de Recursos Humanos como el vocero interno de la organización. Su objetivo dentro de las tácticas de comunicación interna es la de realizar rondas informativas por todas las áreas, comunicando:

○ Situación actual de la empresa.

- Medidas a tomar a partir del accidente. 
- Garantía de seguridad como el valor más importante de la aerolínea.

Para esta táctica, es importante tener en cuenta mensajes clave relacionados al core del negocio y que transmitan seguridad y calma por parte de la organización (anexo 8). Las comunicaciones que surjan hacia los colaboradores deberán resaltar el siguiente mensaje: la seguridad es un valor y tomaremos las medidas necesarias para garantizarla.

\section{. Speech interno para los trabajadores}

Informar a los clientes internos sobre lo ocurrido debe hacerse de manera muy cautelosa. En ese sentido, se preparará un breve resumen sobre los hechos, a ser compartido en los canales internos de la organización.

De este modo, los colaboradores podrán enfrentar las preguntas en los espacios informales a los que recurran, dentro y fuera del espacio laboral.

Con ello, se promoverá que los rumores no se apoderen del entorno y que las respuestas y conversaciones de los colaboradores estén alineadas a los hechos y a la gestión para salvaguardar la imagen de la aerolínea. 


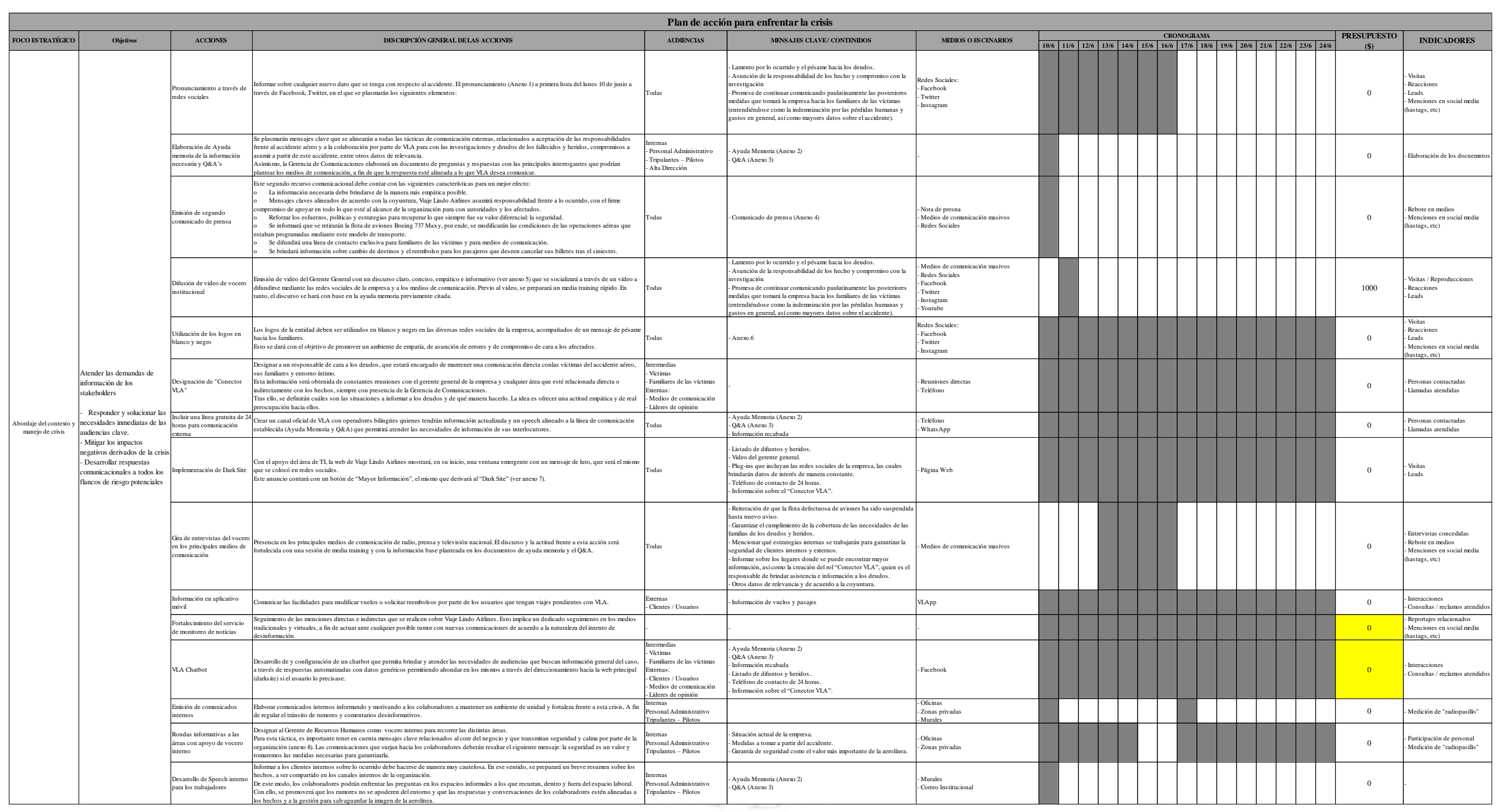




\subsection{Plan de acción postcrisis}

En este punto de acción, es importante que la empresa embarque sus esfuerzos hacia el control de daños que provocó la situación desarrollada a lo largo de este trabajo, así como la prevención de una posterior crisis, sea por las mismas o diferentes razones, pues la experiencia vivida ya marcó un hito negativo dentro de la historia de Viaje Lindo Airlines.

Calahorro (2006:50-54) explica sobre un plan organizado de superación de crisis, para lo cual refirió a cuatro frases mencionadas por Cutlip y Center:

1. Investigación y evaluación de los impactos en los diferentes públicos con sus reacciones, acertadas o no, según la información recibida.

2. Planificación estratégica para recuperar la credibilidad, los públicos, los clientes, incluso con campañas de relaciones públicas, tratando de evitar que permanezca el "recuerdo de la crisis".

3. Ejecución. Se menciona que "debe caracterizarse por su espontaneidad, naturalidad, oportunidad y adecuación a las circunstancias. La comunicación juega un papel importante para modificar actitudes y opiniones" (p.53).

4. Evaluación y análisis de resultados sobre las actuaciones y programas que se han desarrollado para la superación de esta crisis.

Asimismo, como resultado de la crisis por el accidente aéreo, se han detectado los siguientes daños a los que Viaje Lindo Airlines se vio expuesto:

- Desconfianza por parte de los clientes.

- Impacto en la reputación.

- Consecuencias legales, normativas y regulatorias (stakeholders estatales).

- Decrecimiento económico. 
- Inestabilidad interna; incertidumbre.

- Impacto en el atributo de marca mejor posicionado: la seguridad; incoherencia con el valor corporativo.

Con base en estos puntos, y con el fin de realizar un control de daños y gestión adecuada de crisis, se plantearán las estrategias y acciones que estarán bajo la competencia de la Gerencia de Comunicaciones.

Las estrategias determinadas por cada eje se desarrollarán a lo largo del periodo de un año, y son las siguientes:

\section{Control de daños}

Prevención de crisis

- $\quad$ Entrega de brazaletes (Anexo 9)

- Video explicativo de mecanismos de seguridad adoptados e impacto medio ambiental

- $\quad$ "Día de la Seguridad VLA"

- Ampliación de la pauta publicitaria en medios de comunicación. (Anexo 10)

- Reuniones de presentación de avances y mejoras internas con entidades regulatorias.

- Decrecimiento económico.

- Estudio de clima y comunicación interna.

- Plan de acción de clima y comunicación interna.

\section{- Prevención de crisis}

- Reinstalación de un nuevo gabinete de crisis.

- Actualización y socialización del manual de gestión de crisis.

- Apoyo en la convocatoria para análisis psicológicos de trabajadores.

- Media training periódico a la alta dirección de la empresa.

- Acciones conjuntas y soporte comunicacional al Área de Responsabilidad Social Empresarial

- Actualización constante a la alta dirección sobre las novedades en la industria de la aviación.

- Creación de red social corporativa. 


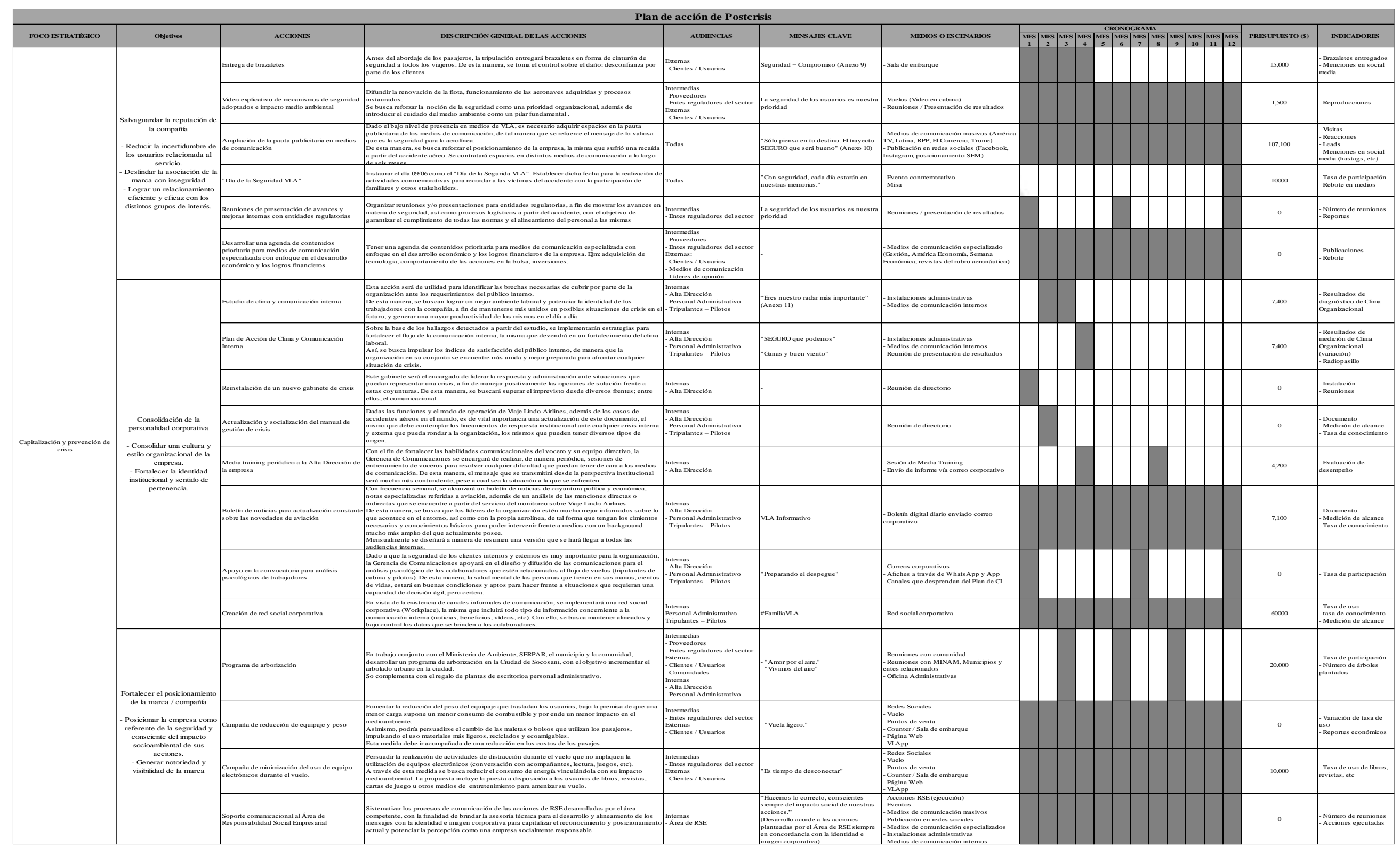




\section{JUSTIFICACIÓN}

3.1. Justificación de Plan de Acciones frente a la crisis

Las acciones que harán frente inmediato a la crisis por el accidente aéreo de Viaje Lindo Airlines, así como las correspondientes a la postcrisis se basan en conceptos importantes dentro del ámbito de la comunicación corporativa.

Inmediatez. Dado que es prioritario anticiparse a todo tipo de rumores, además de brindar respuestas rápidas frente a las situaciones de crisis y la exigencia de la población, las estrategias planteadas buscan brindar una constante e inmediata comunicación desde los canales oficiales de Viaje Lindo Airlines para reducir en lo máximo posible la expansión de rumores y de desinformación.

Empatía y cercanía. Se busca que la organización genere un vínculo con los deudos de las víctimas. Si bien esto será un reto desde todos los puntos de vista, ofrecer disculpas y apoyo en todo el proceso, desde la modificación de un logo hasta un discurso del líder máximo de la organización serán valiosos y bien recibidos, lo que estrecha la relación y genera una sensación de empresa comprometida entre dicho grupo de personas.

Comunicación consecuente. En vista a que el principal valor de Viaje Lindo Airlines ha sido siempre el de la seguridad, el accidente aéreo causó un impacto negativo que debía ser combatido. Mantener informada a la población sobre las acciones que VLA realizará para garantizar la seguridad más que nunca busca que la comunicación de la empresa esté alineada con la imagen que desea proyectar y fortalecer.

Las acciones durante la crisis obedecen, principalmente, a estas premisas. Para ello, nos valemos de diversos recursos cuyos esfuerzos, sumados, brindarán a la propuesta para enfrentar esta situación de crisis nunca antes vivida, un punto de quiebre del que se busca salir fortalecidos.

3.2. Justificación de estrategias para el control de daños y prevención postcrisis

Por otro lado, realizar un plan anual de acciones para mantener un control de la situación era vinculante, a fin de construir nuevas estrategias para atenuar los daños 
anteriormente citados, así como para prevenir futuras situaciones que representen potenciales crisis, ya sean de naturaleza similar o totalmente distintas.

\subsubsection{Justificación de estrategias para el control de daños}

Como mencionamos líneas arriba, se han detectado siete principales daños a la organización, ocasionados por el accidente con el avión Boeing 737 Max, lo cual se ha combatido con propuestas que buscan lo siguiente:

- Combatir la sensación de inseguridad.

- Hacer más visible a la marca y reposicionarla en el mercado.

- Mantener una relación sólida y transparente con las autoridades.

- Generar una mejor relación interna con los colaboradores y atender sus necesidades, a fin de impulsar el clima laboral de la entidad.

Este último punto resulta muy importante, pues los colaboradores resultan unos embajadores externos de la empresa con su entorno. Ello es soportado en que se ve "al clima laboral como una dimensión fundada a partir de las percepciones de las personas y que tiene existencia en cuanto que hay una visión compartida, extendida en el grupo o la organización [...] y coincide con la visión socio cognitiva de las organizaciones" (Edel, 2007, p. 33).

Se hace hincapié en que resolver el último punto representará una mejora importante, dado que el trabajo de los clientes internos tiene repercusión en la productividad con miras a la imagen hacia el público en general, generará mayor estabilidad y prevendrá la incertidumbre frente a otros posibles casos de crisis futuros.

\subsubsection{Justificación de estrategias para la prevención de crisis}

Con el objetivo de estar preparados para una crisis, es esencial tener al equipo técnico preparado para poder explicar cualquier situación, en cualquier momento. Es por eso que un aspecto muy importante en este eje es el del fortalecimiento de las habilidades comunicacionales de la línea directiva.

Esto se soporta en lo estipulado por Cossio (1973), quien menciona que "la opinión pública voceada es opinión autorizada, porque emerge del círculo de la opinión técnica 
y para erigirse como tal tiene que ser una persona que esté en el candelero. Esta situación la alcanza porque la opinión pública lo coloca en ella”.

De esto deviene que se podrán evitar los rumores cuanto más anticipadamente se actúe desde el ámbito de la comunicación. Por otra parte, resulta también relevante trabajar en lo relacionado a un manual de gestión de crisis, pues mostrará una responsabilidad construida a partir de los aprendizajes de la empresa a lo largo de su historia, lo que también permitirá a VLA enfrentar con altos estándares, cualquier tipo de situación que le genere complicaciones indeseadas. 


\section{RECOMENDACIONES}

A continuación, detallaremos las recomendaciones:

- Sea cual fuese la situación, la respuesta frente a la crisis debe ser lo más inmediata posible. De no tener demasiada información sobre el tema en cuestión, sincerarlo. Siempre transparentar lo ocurrido tendrá un mejor recibimiento que mantener silencio y dejar que otros espacios hablen por la propia

organización.

- Recomendamos que el Plan de Gestión de Crisis de la organización sea correctamente socializado entre la alta dirección y constantemente actualizado de presentarse accidentes en el mundo cuya ocurrencia no esté contemplada en el documento que actualmente se tiene. De esta manera, la organización estará con una preparación más idónea de cara a este tipo de situaciones.

- Viaje Lindo Airlines debe administrar los canales oficiales de las comunicaciones entre colaboradores, a fin de evitar que surjan rumores o desinformaciones entre los mismos y que, sobre todo, puedan tener un impacto externo que perjudique la imagen y reputación de VLA.

- Es de vital importancia propiciar una relación más estrecha entre la alta dirección y la Gerencia de Comunicaciones, de manera que el trabajo y el flujo de información entre ambas sea más fluida y mejor consolidada.

- Debe considerarse que cada área pueda responder o tener poder decisorio frente a situaciones de crisis, a fin de no entrampar las comunicaciones en caso de comunicaciones o alertas por parte de proveedores en días inactivos laboralmente hablando. De esta manera, se podrá actuar inmediatamente o en la brevedad posible, tal y como el contexto lo requiera.

- Se recomienda trabajar constantemente en el fortalecimiento de la salud mental del equipo interno de Viaje Lindo Airlines. Esto siempre será benéfico, pues implicará que los colaboradores se encuentren aptos para las diversas tareas y 
contextos que puedan enfrentar, así como que estos perciban empatía y un sentido de importancia por parte de la compañía. 


\section{REFERENCIAS}

- Calahorro, F. M. (2006). Gestión técnica y de la comunicación en situaciones especiales: (crisis, emergencias y negociación). Retrieved from https://books.google.es/books/about/Gesti\%C3\%B3n_t\%C3\%A9cnica_y_de_la_comu nicaci\%C3\%B3n.html?id=Eb1sAAAACAAJ\&pgis=1

- Castells, M. (1997). La era de la información: economía, sociedad y cultura. Vol. 2 el poder de la identidad. 44121 CIC-UCAB/0392 20040218 GR.

- Cossío, C (1973). La Opinión Pública. Editorial Paidós (p. 100).

- ICITEX (2010). Manual de gestión de la comunicación en situaciones de crisis (p.10).

- Edel, R. (2007). Clima y Compromiso Organizacional, Volumen 1. México: ISBN-13: 978-84-691-0999-1, Nº Registro: 08/9869.

- Federación Asturiana de Empresarios (2016). Comunicar en la empresa: del porqué al cómo (p. 124)

- https://www.iata.org/publications/Documents/social-media-crisis-communicationsguidelines.pdf

- https://logicactivity.com/Estudios/GestiondeCrisisAerolineas.pdf 


\section{LISTA DE ANEXOS}

Se adjuntan los siguientes anexos:

Anexo 1: Pronunciamiento breve y conciso a través de redes sociales (Facebook y Twitter).

- $\quad$ Anexo 2: Ayuda memoria

- $\quad$ Anexo 3: Documento de preguntas y respuestas

Anexo 4: Comunicado de prensa

Anexo 5: Discurso del vocero para video de redes sociales

Anexo 6: Publicaciones en redes sociales de la empresa con logos en blanco y negro

\section{Anexo 7: Dark Site}

Anexo 8: Afiche interno para visita a las áreas de la organización

Anexo 9: Diseño de brazaletes para entregar a pasajeros

- $\quad$ Anexo 10: Flyer publicitario para redes sociales

Anexo 11: Afiche de socialización de estudio de clima y comunicación interna

- Matriz Táctica: Plan de acción de control de daños y postcrisis

En el presente documento, se considerarán aquellos que no representen piezas gráficas. 


\section{Anexo 2 - Documento de ayuda memoria}

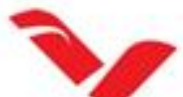 \\ viajelindo}

\section{Documento de ayuda memoria}

\section{Antecedentes y caso}

En mayo del presente año, nuestro proveedor Boeing nos proveyó de los nuevos aviones 737 , los mismos que iniciaron operación a partir del 1 de junio

El viernes 7 de junio, Viaje Lindo Airlines recibió la información por parte de Boeing sobre fallos en las alas en un "reducido número" de sus aviones 737. Dichos datos no llegaron de manera inmediata a nuestras áreas correspondientes.

El domingo 9 de junio, a las 7:35 a. m., un vuelo Lima-Arequipa con 142 pasajeros a bordo, 6 tripulantes de cabina y 2 pilotos reportó fallas en la estabilidad del avión al aproximarse al Aeropuerto Internacional Rodriguez Ballon, en la fase de descenso. Al estar sobre la ciudad de Socosani, el piloto anunció una pérdida de control de la aeronave a la torre de control, para luego solicitar un aterrizaje de emergencia.

Lamentablemente, el accidente tuvo un saldo de 67 pasajeros y tres tripulantes de cabina fallecidos, además de múltiples heridos.

\section{Posición de Boeing}

Cuando Boeing detectó la falla en sus slats, las mismas que brindan funcionamiento a las alas y aerodinámica del avión durante el despegue y aterrizaje, dio estos datos a conocer a través de un comunicado de su oficina de comunicaciones, y divulgado por medios de comunicación. Además, contactó a las aerolineas que recibieron un lote reciente en los últimos 8 meses

- Av. Elmer Faucett s/n, Callao 07031 Aeropuerto Jorge Chávez.

ᄂ (511) $517-3100$ (511) $511-6055$

0 info@viajelindo.com

X www.viajelindo.com 


\section{viajelindo}

\section{Datos coyunturales}

- El presidente de la República ha declarado el duelo nacional

- Esta coyuntura adversa también ha representado ataques por otros frentes: se filtró la información de que VLA no ha cumplido con el pago de sus derechos laborales, que las condiciones de trabajo no son las más óptimas, entre otros.

- La opinión pública ha puesto en tela de juicio el valor más importante de nuestra organización: la seguridad.

\section{Mensajes a transmitir:}

- Estamos realmente consternados y extendemos nuestras más sentidas condolencias hacia los familiares que han perdido a sus seres queridos a causa de este accidente aéreo.

- En consecuencia a nuestras responsabilidades, Viaje Lindo Airlines se compromete a cubrir todos los gastos de hospital, funeral y entierro de las víctimas del accidente aéreo, además de los montos extra que hagan falta.

- Colaboraremos con las autoridades en todas las investigaciones que sean necesarias para esclarecer la totalidad del caso.

- Estamos propiciando reuniones con Boeing para analizar los daños y hacer una revisión exhaustiva de toda la flota de la que dicha empresa sea proveedora.

- Asimismo, hemos procedido a suspender la flota de aviones Boeing 737 Max de nuestras operaciones aéreas. Los vuelos que tenian designados dichas aeronaves para sus operaciones serán reemplazados.

- Aquellos usuarios que deseen reprogramar sus viajes pueden hacerlo a través de nuestra aplicación o página web. Asimismo, quienes quieran la devolución por cancelación de viaje, por favor, contactarse a nuestra linea de atención al cliente.

- Exhortamos a que el público en general visite nuestro Dark Site, un espacio en nuestra web en donde encontrarán toda la información relacionada a esta lamentable tragedia. El vinculo también ha sido compartido en nuestras redes sociales.

- Hemos habilitado un teléfono de emergencias para el entorno de las víctimas, en el que también brindaremos información y ayuda psicológica.

- Av. Elmer Faucett s/n, Callao 07031 Aeropuerto Jorge Chávez.

C. (511) $517-3100$ (511) $511-6055$

a infoQviajelindo.com

X www.viajelindo.com 


\section{Anexo 3 - Documento de preguntas y respuestas}

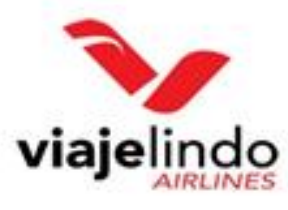

\section{Documento de preguntas y respuestas}

¿Por qué ocurrió este accidente y qué tanta responsabilidad tiene VLA en él?

El accidente aéreo ocurrió debido a una falla en las alas de avión Boeing 737 Max, nuestro proveedor. Sin embargo, también ha existido una descoordinación entre las áreas de nuestra empresa, lo que evitó que tomemos las decisiones adecuadas a tiempo. Por ello, en conjunto con nuestro proveedor, asumimos las responsabilidades del caso y colaboraremos con los deudos y las autoridades en todo lo que resulte necesario. Lamentamos profundamente este suceso

¿De qué manera se apoyará a los deudos de las víctimas?

Viaje Lindo Airlines se compromete a cubrir los gastos fúnebres, asi como de hospitales y tratamiento psicológico para los sobrevivientes y familiares de las victimas de este penoso accidente. También habilitaremos un vuelo para trasladar a estos familiares a la zona del siniestro, a fin de que puedan realizar las gestiones

\section{¿Qué nos garantiza que este tipo de accidentes no se repetirán?}

Desde Viaje Lindo Airlines, estamos con todos los esfuerzos concentrados en realizar una revisión exhaustiva de todos los aviones con los que operamos. Para ello, nos estamos valiendo de especialistas de nuestras empresas proveedoras. Asimismo, fortaleceremos las politicas internas de seguridad de nuestra organización, con mayor hincapié en la capacitación y evaluación de nuestros pilotos y tripulación.

- Av. Elmer Faucett s/n, Callao 07031 Aeropuerto Jorge Chávez.

C (511) $517-3100$ (511) $511-6055$

info@viajelindo.com

X www.viajelindo.com 


\section{viajelindo}

¿Qué medidas internas se están tomando con los responsables de este fatal accidente?

Estamos realizando una investigación profunda para la separación inmediata de nuestra empresa de quienes sean encontrados responsables o estén involucrados en la omisión de información para la ocurrencia de este accidente. Además, estamos propiciando reuniones con Boeing para analizar los daños y hacer una revisión exhaustiva de toda la flota de la que dicha empresa sea proveedora.

\section{¿Cuál va a ser el canal de comunicación para con los deudos?}

Hemos lanzado una linea telefónica para atención y ayuda a los deudos, la misma que estará activa las 24 horas del dia. Asimismo, hemos designado a nuestro "gestor de la seguridad", quien será el encargado de la comunicación entre los familiares de las víctimas y la alta dirección de VLA, con el fin de apoyarlos lo más posible en sus requerimientos e inquietudes.

Los usuarios también contarán con el Dark Site, un espacio habilitado en la web de nuestra empresa, y en donde los familiares de las víctimas y medios de comunicación en general puedan encontrar información oficial actualizada constantemente.

- Av. Elmer Faucett s/n, Callao 07031 Aeropuerto Jorge Chávez.

C. (511) $517-3100$ (511) 511-6055

infoQviajelindo.com

X www.viajelindo.com 
$\begin{array}{llllll}\text { Anexo } & 4 & - & \text { Comunicado } & \text { de } & \text { prensa }\end{array}$

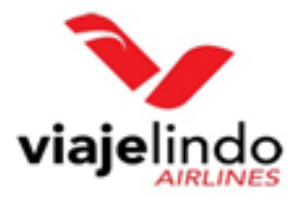

\section{Comunicado de prensa}

En Viaje Lindo Airlines (VLA), lamentamos profundamente la pérdida de las 70 valiosas vidas, tras el accidente aéreo ocurrido el último domingo en la ciudad de Socosani, en el vuelo Lima - Arequipa, operado por una aeronave Boeing 737 Max de nuestra flota

Nuestra aerolinea ofrece sus más sentidas condolencias a los familiares y seres queridos de las víctimas, e informa que asumirá los gastos fünebres y de salud de las personas que permanecen heridas, como parte de la responsabilidad compartida con su proveedor, Boeing

Asimismo, VLA s ha procedido a retirar la flota de aviones Boeing $737 \mathrm{Max}$, por lo que los vuelos que tengan asignadas dichas aeronaves podrán ser modificados o cancelados a través de la página web o el aplicativo móvil de la aerolinea.

Para mayor información, se invoca a que los deudos puedan ingresar a nuestro "dark site" dentro de nuestra página web, en donde podrá encontrar recursos de interés y apoyo, a disposición del público en general, para el seguimiento del caso.

También podrán comunicarse a nuestra linea informativa, espacio creado especialmente para atender las necesidades a partir del accidente aéreo, con el objetivo de impulsar un flujo de comunicación adecuado entre los deudos y la organización.

De esta manera, en Viaje Lindo Airlines estamos comprometidos y listos para brindar asistencia técnica para la investigación del accidente. Redoblaremos nuestros esfuerzos, politicas y estrategias para brindar a todos nuestros viajeros, la seguridad en cada una de nuestras próximas operaciones aéreas.

- Av. Elmer Faucett s/n, Callao 07031 Aeropuerto Jorge Chávez.

ᄂ (511) 517-3100 (511) 511-6055

$\boldsymbol{m}$ info viajelindo.com

X www.viajelindo.com 


\section{Anexo 5 - Discurso del vocero para vídeo de redes sociales}

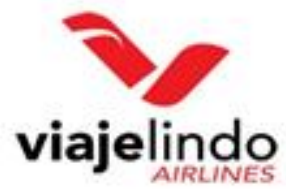

\section{Discurso del vocero para vídeo de redes sociales}

Estimados clientes,

Hace 24 horas, ocurrió una tragedia que, desde Viaje Lindo Airlines, jamás hubiésemos querido que ocurra. Hemos perdido 70 valiosas vidas entre pasajeros y tripulación a causa de un accidente aéreo causado por un desperfecto mecánico de un Boeing $737 \mathrm{Max}$ de nuestra flota.

Nuestros pensamientos y oraciones hacia los familiares de los pasajeros y tripulantes que perdieron su vida. Asumiendo nuestras responsabilidades, Viaje Lindo Airlines se compromete a cubrir todos los gastos de salud y funerales de las víctimas del accidente aéreo, además de brindar todo el apoyo extra que sea necesario.

La seguridad es uno de los valores que más nos importan, y este terrible accidente nos ha golpeado fuertemente dado que, en 15 años de historia, nunca nos habia ocurrido algo similar. Esta sigue siendo nuestra prioridad, por lo que trabajaremos arduamente para lograr fortalecerlo luego de este duro golpe, y para la tranquilidad de todos nuestros usuarios.

Trabajaremos de sol a sombra en los siguientes dias para aseguramos que todos los problemas sean resueltos $y$ esta situación jamás vuelva a repetirse, $y$ hacer de Viaje Lindo Airlines, la aerolinea donde tú seas la prioridad.

Muchas gracias por su atención.

Av. Elmer Faucett s/n, Callao 07031

Aeropuerto Jorge Chávez.

C (511) $517-3100$ (511) 511-6055

info@viajelindo.com

X www.viajelindo.com 